\title{
Plant responses to fluctuating UV environments
}

\section{Barnes, Paul W}

$\mathrm{CABI}$

2017

Barnes , P W , Robson , T M , Tobler , M A , Bottger , I N \& Flint , S D 2017 , Plant responses to fluctuating UV environments . in B R Jordan (ed.), UV-B Radiation and Plant Life : molecular biology to ecology . CABI , Wallingford , pp. 72-89 . https://doi.org/10.1079/9781780648590.0072

http://hdl.handle.net/10138/307050

https://doi.org/10.1079/9781780648590.0072

unspecified

acceptedVersion

Downloaded from Helda, University of Helsinki institutional repository.

This is an electronic reprint of the original article.

This reprint may differ from the original in pagination and typographic detail.

Please cite the original version. 
Cite as: Barnes, P. W., Robson, T. M., Tobler, M. A., Bottger, I. N., \& Flint, S. D. (2017). Plant responses to fluctuating UV environments. I B. R. Jordan (Red.), UV-B $\underline{\text { Radiation and Plant Life: molecular biology to ecology (s. 72-89). Wallingford: CAB }}$ International. DOI: 10.1079/9781780648590.0072

\section{Chapter 6: Plant responses to fluctuating UV environments}

Paul W. Barnes ${ }^{1 *}$, T.M. Robson ${ }^{2}$, M.A. Tobler ${ }^{1}$, I.N. Bottger ${ }^{1}$ and S.D. Flint ${ }^{3}$

${ }^{1}$ Department of Biological Sciences and Environment Program, Loyola University New Orleans, 6363 St. Charles Avenue, New Orleans, Louisiana 70448, USA;

${ }^{2}$ Department of Biosciences, Plant Biology Division, University of Helsinki, PO Box 65, Helsinki, Finland;

${ }^{3}$ Department of Forest, Rangeland and Fire Sciences, UIPO 441135, University of Idaho, Moscow, Idaho 83844-1135, USA.

*Author for correspondence: Email: pwbarnes@loyno.edu; Phone: +1 504.865.2008 


\subsection{Introduction}

The solar ultraviolet (UV; 280-400 nm) radiation regime experienced by plants in nature varies across multiple time scales (inter-annual, seasonal and diurnal). Longterm (year-to-year) variability in UV irradiance at the Earth's surface in modern times is driven largely by changes in stratospheric ozone, which influences the attenuation of ultraviolet-B radiation (UV-B; 280-315 nm), and climate change, which can alter both UV-B and ultraviolet-A radiation (UV-A; 315-400 nm) via changes in cloud cover, aerosols and tropospheric ozone (Bais et al., 2015, Bornman, 2017). Variation in incident UV over shorter time frames (seasonal and diurnal) results primarily from the natural rhythms in prevailing solar angles that occur over a year or day though intra-seasonal fluctuations in ozone can play a significant role in certain regions (Madronich et al., 2011, Bais et al., 2015). These natural cycles in UV irradiance are routinely disrupted by changes in atmospheric conditions and vegetative cover, which themselves can exhibit some degree of seasonal and diurnal periodicities (e.g., pronounced rainy (monsoonal) seasons and phenological patterns in canopy development; Fig. 6.1A). Rapid fluctuations in solar UV can also occur via changes in cloud cover, which can either increase or decrease UV irradiance depending on the position and type of clouds in relation to the solar disk (Fig. 6.1B, C; Thiel et al. (1997), Lopez et al. (2009)), as well as gaps in the canopy that create periodic sunflecks in the understory (Fig. 6.1D; Flint and Caldwell (1998), Heisler et al. (2003), Aphalo (2017)). Consequently, plants and individual leaves can experience considerable change in UV exposure over their life spans, from one day to the next, and within a given day that is both regular and, at times, erratic and unpredictable. 
Over the past several decades, considerable attention has been given to understanding plant responses to changes in average UV conditions that occur as a result of stratospheric ozone depletion and to the interactive effects of enhanced UV-B and other climate change factors (e.g., elevated $\mathrm{CO}_{2}$ and increased temperature; Björn (2015), Bornman et al. (2015) and references therein). By comparison, we know far less about plant responses to changes in solar UV fluxes that occur 1) naturally over the course of a given growing season or day, 2) in response to changes in cloud cover, or 3) as leaves alternate between shaded and sunlit conditions within canopies and in understory environments.

Given that plants have evolved a photosensory system to sense ambient UV-B (Rizzini et al., 2011, Jenkins, 2017) and that this photoreceptor appears to interact with other photoreceptor systems (e.g., cryptochromes and phytochromes) to provide information to a plant about its light environment (Xie and Hauser, 2012, Tilbrook et al., 2013, Mazza and Ballaré, 2015), it is relevant to ask how quickly and to what degree plants can respond to changes in their UV environment, and what these responses might mean for plant fitness. For instance, do rapid fluctuations in UV (seconds to minutes) in fact matter to plants or do they integrate and respond to UV over much longer time frames (hours, days or weeks)? Also, is the rate and magnitude of the response to changing UV conditions contingent upon developmental stage (e.g., young vs. old leaves) and environmental factors that influence resource availability and levels of physiological stress (e.g., atmospheric $\mathrm{CO}_{2}$ concentration, temperature and moisture availability)? Finally, what is the adaptive significance of variation among plant species in their abilities to respond to temporal fluctuations in UV and what might these differences 
mean for the timing of defenses against other abiotic (e.g., drought) and biotic (e.g., herbivory) factors that share commonalities in photosensory signaling (Demkura and Ballaré, 2012) and biosynthetic pathways (Izaguirre et al., 2007) with UV responses?

In this chapter, we review research to date on what is known about the prevalence and mechanisms of plant responses to short-term fluctuations in UV exposure and explore the possible adaptive and ecological significance of these responses. We address only changes in total UV irradiances and not shifts in spectral quality, which can be associated with fluctuating UV conditions particularly in understory environments (Parisi and Kimlin, 1999). Our emphasis is on physiological responses to UV, and we specifically focus on UV screening protection as this is a primary avenue of UV acclimation and one of the most frequently documented and readily observable responses to UV in plants (Searles et al., 2001).

\subsection{Overview of plant responses to $U V$ and the time course of $U V$ acclimation}

Abundant evidence from studies conducted in controlled environmental conditions indicates that exposure to UV can elicit specific photomorphogenic responses in plants as well as induce a variety of effects that are generally considered to be detrimental to plant function (Jansen and Bornman, 2012, Li et al., 2013, Robson et al., 2015). The highly energetic shorter wavelengths of UV (i.e., UV-B) are particularly efficient at producing a number of deleterious effects in plants, including disruption of the integrity and function of important macromolecules (DNA, proteins and lipids), oxidative damage, partial inhibition of photosynthesis and growth reduction (Strid and Hideg, 2017). To combat these adverse effects, plants have developed a suite of 
biochemical, physiological and morphological mechanisms that collectively protect or repair sensitive targets from direct and indirect UV-induced injury (Britt, 1999, Favory et al., 2009, Hectors et al., 2009, Jacques et al., 2009, Schreiner et al., 2017). This acclimation to UV appears sufficient to largely minimize any detrimental effects of UV-B on plant growth and productivity when plants are grown under ambient or realistically enhanced UV-B in the field (Ballaré et al., 2011) such that photomorphogenic (and often beneficial) effects of UV generally predominate under these conditions (Wargent and Jordan, 2013, Ballaré and Austin, 2017).

One of the most important and widespread protective responses of plants to UV radiation involves the induction and synthesis of flavonoids, hydroxycinnamic acids (HCAs) and other related phenylpropanoid compounds that function as "UV sunscreens" and antioxidants (Caldwell et al., 1983, Agati et al., 2012, Emiliani et al., 2013). The accumulation of flavonoids and other UV-absorbing compounds in epidermal tissue decreases epidermal UV transmittance (TUV) but has minimal effect on attenuating photosynthetically active radiation (PAR; 400-700 nm) needed for photosynthesis of underlying mesophyll tissue (Fig. 6.2; Day et al. (1994), Mazza et al. (2000), Bidel et al. (2007)). The epidermal screening of UV is a primary avenue by which plants acclimate to changing UV environments, including alterations resulting from stratospheric ozone depletion and climate change (Williamson et al., 2014, Bornman et al., 2015). This UV acclimation response entails a measurable energetic and fitness cost (Snell et al., 2009, Guidi et al., 2011, Hofmann and Jahufer, 2011), varies within and among species (Day et al., 1992, Qi et al., 2010, Randriamanana et al., 2015) and is linked with cross-tolerance 
to other abiotic and biotic stresses (e.g., drought, herbivory and pathogen infection; Mewis et al. (2012), Bandurska et al. (2013), Zavala et al. (2015)).

Flavonoid biosynthesis is influenced by UV-B as well as UV-A, PAR (Flint et al., 2004, Siipola et al., 2015) and other environmental factors, such as temperature (Bilger et al., 2007). Orchestration of UV-B-induced flavonoid biosynthesis appears to involve the UV-B photoreceptor UV RESISTANCE LOCUS 8 [UVR8] (Jenkins, 2014) with UV-B exposure leading to the expression of UVR8-dependent gene transcripts involved in phenylpropanoid metabolism (Morales et al., 2013). While exposure to UV-B has been shown to induce rapid (within minutes) activation of UVR8 (Kaiserli and Jenkins, 2007), the production and accumulation of UV-absorbing compounds and resultant decrease in Tuv typically occurs over much longer time frames (i.e., days; Fig. 6.3A; Hectors et al. (2014), Bidel et al. (2015), Wargent et al. (2015)). During this period of acclimation, leaves may be susceptible to UV-induced injury (e.g., inhibition of photosynthesis; Wargent et al. (2015)). Prolonged exposure to UV-B eventually leads to reduced sensitivity to UV and may even enhance photosynthetic performance and provide some protection against photoinhibition (Wargent et al., 2011, Wargent et al., 2015).

The epidermal UV transmittance of leaves is a highly plastic trait and within a given species can vary from $<5 \%$ to near $100 \%$ depending upon the radiation environment (UV and PAR) experienced during leaf development (Fig. 6.3A, B). Thus, leaves that are produced in low UV and/or low PAR environments, such as those in deep shade in canopies or understory environments, or in glasshouses that lack UV, typically display limited UV screening capabilities (Fig. 3A,B; Krause et al. (2003a), Agati et al. (2008), Pollastrini et al. (2011), Barnes et al. (2013)). However, the relationship between 
UV shielding and the light (UV and PAR) regime is strongly non-linear such that leaves that develop under even rather moderate shade can still exhibit relatively high UV protection (low Tuv; Fig. 6.3A-inset; 6.3B). For leaves that do develop under deep shade or very low UV they can be particularly susceptible to UV-induced injury if they suddenly encounter high UV environments. This would occur for certain vegetable crops that are propagated as seedlings in glasshouses or shade structures before being transplanted to the field (Wargent, 2017), shade leaves within plant canopies that are exposed to full sunlight as a result of canopy gaps or perturbations due to herbivory, wind (Fig. 6.1D) or other factors (Kolb et al., 2001, Barnes et al., 2013), and understory plants exposed to periodic sunflecks (Krause et al., 2003b).

\subsection{Responses to sun-shade transitions}

As indicated above, the ability of leaves to adjust their flavonoid levels and UV shielding in response to UV exposure during leaf development is well established. What is less clear, however, is how pliable these UV optical properties are once leaves have matured and developed under one set of conditions and are then confronted with rapid changes in these conditions. Some studies suggest that mature leaves or leaf segments are generally unresponsive in their UV-sunscreen capacities when exposed to sudden changes in environmental conditions such as temperature (Nybakken et al., 2004b, Bilger et al., 2007). Other studies however have shown that the UV-screening response can be more flexible in response to changes in the light environment (Krause et al., 2007, Agati et al., 2011, Morales et al., 2011, Bidel et al., 2015). For example, field studies with fully developed sun and shade leaves of Populus tremuloides (aspen) and Vicia faba (fava 
bean) have shown that there can be considerable flexibility in UV acclimation in mature leaves, at least for those produced under low light conditions (i.e., shade leaves; Fig. 6.3C). Specifically, shade leaves were shown to decrease $T_{U v}$ when transferred to sun environments, but sun leaves did not change their UV sunscreen protection when suddenly exposed to shade conditions (Barnes et al., 2013). Although increases in UV shielding were detected 1-2 days following the transfer of plants from shade to full sun conditions, full transition of shade leaves to the equivalent protection of sun leaves required 4-10 days depending on species and conditions. These changes in leaf optical properties were generally associated with increases in UV-absorbing compounds. Similarly Krause et al. (2004) showed that mature leaves of tropical understory plants can also respond to abrupt increases in solar UV radiation by increasing UV-absorbing compounds. In the case of $P$. tremuloides and $V$. faba, this adjustment in epidermal UV transmittance of shade leaves required both UV-B and UV-A, whereas PAR and UV were involved in the establishment of UV sunscreen protection during leaf development (Barnes et al., 2013). Similarly, Bidel et al. (2015) showed that UV-B was required to induce additional UV shielding in mature leaves of Centella asiatica. Thus, relatively high levels of PAR appear to provide a high foundation of UV-protection, which then is further enhanced by UV exposure (Götz et al., 2010, Wargent et al., 2015).

\subsection{Seasonal and diurnal changes in UV-sunscreen protection}

\subsubsection{Occurrence and patterns among species and environments}

The above studies indicate that mature leaves can, in some cases, respond, albeit relatively slowly, to sudden changes in their UV environment. Additionally, there is now 
growing evidence that fully developed leaves can modulate their levels of UV sunscreen protection on more rapid time scales such as one day to the next or over the course of an individual day. The earliest report suggesting that plants may be capable of rapid adjustment in UV-screening came from observations by Lautenschlager-Fleury (1955) who found that the UV-B transmittance of epidermal peels from Vicia faba leaves was low during midday on a sunny day but remained relatively high on a cloudy day. Subsequently, Sullivan et al. (2007) detected significant day-to-day changes in UVabsorbing compounds in field-grown Hordeum vulgare (barley) and Glycine max (soybean) and this variation was correlated with variation in ambient UV-B in both species and UV-A in soybean. This variability was dampened in plants grown under reduced (near $90 \%$ reduction) levels of UV-B and no significant relationship was found between variation in solar UV and UV-screening compounds in these plants. By comparison, Kotilainen et al. (2010) found no clear relationships between UV doses and seasonal variation in flavonoids and other phenolics in Alnus incana (alder) and Betula pubescens (birch) leaves. Other investigators have also shown that flavonoids and epidermal UV screening can vary over the course of a season (Fischbach et al., 1999, Liakoura et al., 2001, Louis et al., 2009, Nenadis et al., 2015) though it is sometimes difficult to assess whether this variation is the result of UV acclimation during leaf development as opposed to rapid adjustment in fully developed leaves, especially in species that produce long-lived leaves and multiple leaf cohorts/season.

The first evidence that plants could adjust levels of UV photoprotection on a diurnal basis came from field studies conducted by Veit et al. (1996) who found that the concentration of flavonoids from whole-leaf extracts of Anacardium excelsum, a tropical 
tree, and Cryptogramma crispa, an alpine fern, increased progressively during the morning and then declined in a similar fashion in the afternoon in both species. More recently, Barnes et al. (2008) used chlorophyll fluorescence (UVA-PAM; Kolb et al. (2005) to non-invasively measure epidermal UV-A shielding and reported small (ca. 1$2 \%$ change in absolute $\mathrm{T}_{\mathrm{UV}} ; 13-16 \%$ change in relative $\left.\mathrm{T}_{\mathrm{UV}}\right)$, but statistically significant diurnal changes in epidermal UV transmittance in three plant species (Vicia faba, Oenothera stricta and Verbascum thapsus) growing in a high-UV tropical alpine environment in Hawaii. Following this study, Barnes et al. (2016a) surveyed 37 species (63 taxa of wild and cultivated species with multiple cultivars/species for several cultivated species) growing in different locations (Hawaii, Utah, Idaho and Louisiana, USA) and found that diurnal change in TUv occurred in nearly half of the species examined. Diurnal changes in $\mathrm{T}_{\mathrm{UV}}$ were found in plants at all locations, in monocots as well as dicots and in both herbaceous and woody growth forms. Species that did not exhibit diurnal change in TUv included grasses and dicots of cultivated, wild and exotic species (e.g., Symphoricarpus albus, Zea mays, Phalaris arundinacea and Malva parviflora), and in some cultivated species (Brassica rapa, Triticum aestivum, and Citrullus lanatus) there was significant intraspecific variation in the prevalence of this phenomenon. Diurnal changes in flavonoid levels have also been observed in Centaurea uniflora and Geum montanum, two herbaceous alpine species growing in the French Alps, using similar non-invasive techniques (i.e., Dualex; Goulas et al. (2004); T. Robson and S. Hartikainen, unpubl. data; Fig. 6.4). Thus, diurnal adjustment in UV sunscreen protection appears not limited to species in extreme UV environments but is in fact widespread among higher plants. However, at present there appears to be no apparent 
functional or ecological distinction between diurnally 'responsive' vs. 'unresponsive' species.

Results from the above survey study further revealed that significant interspecific variation existed in the magnitude of these diurnal changes in epidermal UV transmittance. Certain species, such Abelmoschus esculentus (okra) displayed large (62\% relative change) decreases in $\mathrm{T}_{\mathrm{UV}}$ from dawn to midday (absolute $\Delta \mathrm{T}_{\mathrm{UV}}=16.1 \%$; Fig. 4A) whereas others, such as Typha latifolia, showed minimal diurnal changes in $T_{U v}$ of over the day $\left(\Delta \mathrm{T}_{\mathrm{UV}}<1 \%\right)$. Across taxa and locations, the largest diurnal changes in $\mathrm{T}_{\mathrm{UV}}$ were found for plants growing in locations with warm nights (i.e., Louisiana). Low temperatures are known to induce the production of flavonoids (Neugart et al., 2013) and decrease TUv (Bilger et al., 2007), such that many plants growing in cold, high-elevation or high-latitude sites often exhibit high constitutive levels of UV sunscreen protection (Barnes et al., 2000, Nybakken et al., 2004a, Albert et al., 2009). The small diurnal changes in $\mathrm{T}_{\mathrm{Uv}}$ observed in plants from cooler locations (temperate latitudes and high elevations) may thus be a consequence of low temperature effects on UV-absorbing compounds, which then restricts the range of diurnal transmittances possible in these species. Interestingly, across all taxa and locations the magnitude of $\Delta \mathrm{T}_{\mathrm{UV}}$ and the daily minimum value of $\mathrm{T}_{\mathrm{UV}}$ (midday values) were not correlated with daily UV fluxes or the amplitude of diurnal changes in solar UV-B irradiance. The magnitude of the diurnal changes in epidermal UV transmittance therefore appears to be governed more by nighttime values of $\mathrm{T}_{\mathrm{Uv}}$ than those at midday. Collectively, these findings suggest that the largest diurnal changes in TUv will likely occur in plants inhabiting warm subtropical and tropical environments. 


\subsubsection{Mechanisms and drivers}

Although diurnal adjustment in UV shielding appears common among plant species, the underlying mechanisms and drivers of these rapid responses remain unclear. Direct transmittance measurements made on epidermal peels of $V$. faba have confirmed that the rapid changes in $\mathrm{T}_{\mathrm{UV}}$ measured using chlorophyll fluorescence are indeed the result of changes in the optical properties of the epidermis (Barnes et al., 2016b). These diurnal alterations in $\mathrm{T}_{\mathrm{UV}}$ are further associated with changes in the levels of whole-leaf UV-absorbing compounds in responsive species (e.g., A. esculentus and Solanum lycopersicum) but this is not the case for unresponsive species (e.g, Zea mays; Barnes et al. (2015), Barnes et al. (2016b)).

How plants actually achieve these rapid and reversible changes in UV-screening and flavonoids remains is not known. As indicated above, the induction and accumulation of UV-absorbing compounds and resultant decreases in $\mathrm{T}_{\mathrm{UV}}$ typically occur over time frames (days) considerably longer than these rapid changes (Hectors et al. 2014; Wargent et al. 2015). The relocation of flavonoids among different pools in leaf tissues (Schnitzler et al., 1996, Burchard et al., 2000), the rapid alterations in absorptive properties of individual compounds (e.g., Dean et al. (2014)) and/or the UV-induced conversion of phenylpropanoid structures (e.g., Boulton, 2001) would seem more likely mechanisms to account for the rapid changes in these UV-sunscreens than de novo synthesis and degradation of these compounds. Indeed, relatively rapid changes ( $<1$ day) in the flavonoid composition of leaves have been observed in several plant species. For example, after one day of moderate UV-B exposure, Neugart et al. (2012) found that 
leaves in juvenile plants of Brassica oleracea showed a number of structurally-dependant changes in flavonol (quercetin and kaempferol) glycosides with some compounds increasing and others declining. Similarly, Barnes et al. (2016b) found significant diurnal shifts in the foliar composition of quercetin glycosides in A. esculentus with low molecular weight compounds changing to a greater degree than higher weight compounds. Because of the nature of these studies there was no way to ascertain the precise cellular location of these compounds and thus it is unclear whether these compounds function primarily as UV sunscreens or as antioxidants.

It is conceivable that this diurnal change in UV-shielding represents some aspect of an endogenous circadian rhythm in plants (McClung, 2001). Indeed, diurnal rhythms in gene expression, metabolites and the activities of key enzymes involved in phenylpropanoid biosynthesis (e.g., chalcone synthase) are known to occur (Peter et al., 1991, Kim et al., 2011), and the circadian clock in Arabidopsis thaliana appears to interact with UVR8-controlled UV-B signaling (Feher et al., 2011). Whether these rapid UV-shielding responses are mediated all or in part by the UV-B photoreceptor UVR8 is unknown at present. Several studies have, however, demonstrated that manipulation of the light regime can significantly influence these diurnal changes. For example, Barnes et al. (2008) showed that the imposition of dense shade at different times of the day could effectively eliminate diurnal changes in $\mathrm{T}_{\mathrm{Uv}}$ in Verbascum thapsus, and conversely, the removal of shade caused $\mathrm{T}_{\mathrm{UV}}$ to revert to "normal" conditions within a matter of minutes. Subsequent studies with A. esculentus showed that the diurnal adjustment in $\mathrm{T}_{\mathrm{UV}}$ in this species could be reduced by ca. 50\% when plants were placed under plastic film that attenuated much of the ambient solar UV (Barnes et al. 2016). Also, the diurnal changes 
in UV-shielding in this species and others are usually less pronounced on cloudy than sunny days and for $A$. esculentus there is a strong negative correlation between $\mathrm{T}_{\mathrm{UV}}$ during the day and incident UV-B and PAR when data from clear and cloudy days are combined (Barnes et al., 2016b). Field filter experiments by Robson and Hartikainen (unpubl.) have also shown that diurnal change in epidermal flavonoids in Centaurea uniflora was not detectable when plants were kept in continuous darkness or when UV-B or UV-B + UV-A was filtered out of sunlight (Fig. 6.4). Removing blue and UV radiation produced a diurnal pattern somewhat different than that of plants experiencing full sunlight. These findings are consistent with those of Veit et al. (1996) who reported that removal of solar UV-B eliminated the diurnal changes in flavonoids in their study species and the studies of Sullivan et al. (2007) who found a significant positive correlation between day-to-day variation in UV-absorbing compounds and ambient solar UV-B. Thus, it appears that these rapid changes in leaf optical properties represent a specific response to sunlight (UV and perhaps visible) though some involvement with the circadian clock has not been ruled out (e.g., Atamian et al. (2016)).

\subsubsection{Costs, benefits and ecological significance}

Irrespective of mechanisms, these diurnal changes in UV shielding likely provide clear benefits to plants in UV protection, at least when compared to hypothetical situations where low predawn levels of UV shielding remain unchanged throughout the day (Fig. 6.5). However, the benefits of diurnal adjustment in UV protection relative to plants that maintain consistently high (i.e., midday equivalent) levels of UV protection over the day are less clear. In comparison to these kinds of plants (e.g., Z. mays), model 
calculations suggest that plants that exhibit diurnal adjustment in UV shielding (e.g., $A$. esculentus) may experience increased penetration of UV to the underlying mesophyll both in the morning and afternoon but not at midday. This is likely due to the time lag between solar UV change and that of $\mathrm{T}_{\mathrm{UV}}$. It is conceivable that increased penetration of UV to photosynthetic tissue at these times of day may protect leaves from photoinhibition (Wargent et al., 2015) that can occur under high irradiances in the middle of the day. However, studies on $V$. thapsus have shown no correlation between $\mathrm{T}_{\mathrm{UV}}$ and photochemical efficiency $\left(\mathrm{F}_{\mathrm{v}} / \mathrm{F}_{\mathrm{m}}\right)$ when leaves encounter sudden changes in light regime (Barnes et al., 2008). There is evidence that UV-A can drive photosynthesis (Turnbull et al., 2013) and increased penetration of UV-A might thereby increase photosynthesis at times of the day when leaves are light-limited (mornings and afternoons). If this is the case, elimination or reduction in diurnal change in $\mathrm{T}_{\mathrm{UV}}$ could potentially reduce plant carbon gain and growth. Finally, there is the possibility that maintaining constant high levels of flavonoids might interfere with plant growth during the night. Several of the flavonoids induced by UV (e.g., quercetin and kaempferol) are known to interfere with auxin metabolism and transport (Ringli et al., 2008, Kuhn et al., 2011), which in turn could influence plant growth and morphology (Hectors et al., 2012). If this is the case, the benefits of diurnal cycling in UV shielding may lie not in UV protection but rather in other functional roles of flavonoids.

As an initial test to assess the costs and benefits of diurnal changes in UV sunscreen protection we compared the effects of attenuating ambient solar UV on the growth and morphology of two species (A. esculentus and Capsicum annuum) that differed in their UV protection "strategies". Although statistically significant diurnal 
adjustments in $\mathrm{T}_{\mathrm{Uv}}$ were evident in both species, this change was much greater in $A$. esculentus than in C. annuum (Fig. 6.6A). In addition, overall levels of UV screening protection were higher and less affected by UV exclusion in $C$. annuит than $A$. esculentus (Fig. 6.6B). When comparing shoot growth and morphology, it appeared that C. annиuт was influenced by UV exclusion to a greater degree than A. esculentus (Table 6.1). Thus, the species that was more flexible in its UV screening (A. esculentus in this case) was less affected in its growth by UV. Whether these differences in morphological sensitivity to UV are due to these differences in UV screening is difficult to assess, as these species likely differ in other aspects of UV protection (e.g., DNA damage repair, canopy architecture and others), which were not examined in this study. Nonetheless, these findings do suggest that, at the very least, there are no clear negative consequences in terms of UV effects on growth and production for species exhibiting diurnal changes in UV shielding. Additional study is needed to determine if there is any general association between flexibility in UV screening protection and sensitivity to UV-induced alterations in growth and morphology.

Diurnal fluctuations in UV sunscreen protection may also have consequences for the timing of plant responses to other abiotic and biotic stresses (e.g., drought and herbivory) that can vary in severity over the course of a day (e.g., Goodspeed et al. (2012)) and which, in some cases, employ similar suites of secondary compounds for both defense and UV protection (Kuhlmann and Müller, 2010, König et al., 2014). For example, are plants that exhibit diurnal changes in flavonoids more susceptible to attack by herbivores or pathogens early and late in the day than in the middle of the day? No studies to date have explored this possibility but understanding how UV protection 
interacts with these, and other physiological and ecological functions, may be required to fully evaluate the costs and benefits associated with "static" vs. "dynamic" UV protection strategies in plants. 
Table 6.1. Effects of ambient solar UV on the growth, morphology and midday epidermal UV transmittance (Tuv) in Capsicum annuum (pepper) and Ablemoschus esculentus (okra). Data are expressed as \% difference of mean attenuated - mean ambient UV with ambient UV values as the base. Plants in the ambient UV treatment were grown under UV-transparent film (aclar) whereas plants in the attenuated UV treatment were grown under clear film that did not transmit UV-B or UV-A radiation (llumar). Significant treatment differences at $P<0.05(*), P<0.01(* *)$, and $P<0.001(* * *)$ as determined by ANOVA; ns = not significant at $P>0.05 . \mathrm{N}=24$ per species and treatment (I. Bottger, M. Tobler and P. Barnes, unpubl. data).

\section{Capsicum annuum}

\section{Parameter}

Shoot height

Internode length

Leaf area

Leaf dry mass

Leaf mass/area

Shoot dry mass

Midday $\mathrm{T}_{\mathrm{UV}}$
$\%$ difference $P$

$-10.2 *$

$-38.3$

$-22.6$

$-17.4$

5.7

$-11.2$

ns

19.2

\section{Abelmoschus esculentus}

$\%$ difference $P$

$-4.4$

ns

$-16.8$

2.4

ns

$2.8 \quad \mathrm{~ns}$

$1.3 \quad \mathrm{~ns}$

$5.0 \quad \mathrm{~ns}$

$71.9 \quad * * *$ 


\subsection{Practical considerations}

The existence of a temporally dynamic UV sunscreen protection system in plants has a number of important practical implications for how plant UV research is conducted and culturing plants in controlled environments when UV-B (and UV-A) is employed to enhance food plant quality and vigor (Schreiner et al., 2012, Wargent, 2017). For research aimed at quantifying the effects of UV radiation on flavonoids and UV protection it is important that the time of day (and time of year) when samples are collected or leaves are measured be standardized and recorded. For field-grown plants, determination of the seasonality of flavonoid levels should be assessed and sample collections and measurements should then be done at midday during the seasonal peak to provide the best measure of maximal levels of UV protection. As noted by Kotilainen et al. (2010) this seasonal maximum may well differ for different species that are sympatric. Care should also be taken to collect samples/data under similar sky conditions. When plants are grown in controlled environments (growth chambers or greenhouses) artificial sources of UV are typically employed (e.g., UV fluorescent bulbs or LEDs). While it is not yet clear whether plants grown in these environments exhibit "typical" diurnal patterns in UV shielding, it is well known that plants are more susceptible to UV injury in these environments than those grown in the field (Caldwell and Flint, 1994). It is conceivable that this heightened sensitivity to UV, at least for some species, may well be the result of diminished UV sunscreen protection when natural diurnal cycles in UV radiation are muted or absent in controlled environments. In these environments it may be necessary to develop artificial lighting and UV exposure systems that promote natural 
diurnal (and seasonal) adjustments in UV screening so as to promote the beneficial effects of UV-B while avoiding excessive UV injury.

\subsection{Summary and conclusions}

The epidermis of leaves is a selective filter of solar radiation—absorbing much of the potentially detrimental solar UV while transmitting visible wavelengths (PAR) that drive photosynthesis in the underlying mesophyll. The epidermis is also a variable UV filter and the increase in the concentration of UV-absorbing compounds (flavonoids and related phenolics) and resultant decrease in epidermal UV transmittance represents a primary mechanism by which plants acclimate to changing UV environments. Understanding the nature and limitations of this acclimation response is fundamental to evaluating the ecological and agronomic significance of variation in solar UV that occurs over multiple temporal scales (inter-annual, seasonal and diurnal).

Results from a number of relatively recent studies conducted on diverse cultivated and wild plant species reveal that this UV protective mechanism is much more dynamic and flexible than previously thought. While the mechanistic underpinnings of this temporal variation is relatively clear in some cases (e.g., the adjustments of UV shielding and flavonoid levels over ontogenetic time) the basis of other responses (e.g., diurnal changes in UV shielding) are less understood. To date, most studies on rapid responses to UV have focused on herbaceous plants that are adapted to high light environments (i.e., heliophytes); less attention has been given to exploring the temporal dynamics of UV protection in forest understory species (i.e., sciophytes) that are adapted to survive in low light environments but which routinely encounter brief periods of intense UV and 
PAR in sunflecks. Additional studies are also needed to evaluate the adaptive significance of rapid modulation in UV shielding in plants and the potential implications of a dynamic UV protection system for other abiotic (drought, nutrient limitation and temperature extremes) and biotic factors (herbivore and pathogen protection) that are cross-linked to this UV protection response.

\subsection{Acknowledgements}

The research described here was supported, in part, by funds from the Louisiana Board of Regents (SURE/NSF grant LEQSF-EPS (2013)-SURE-85 to Loyola University), the US National Science Foundation (NSF Ecosystems Grant DEB0815897), the US Department of Agriculture UV-Monitoring Program (USDA-CSREES No. 2004-34263-14270 to Utah State University via subcontract with Colorado State University), the Utah Agricultural Experiment Station, the Loyola University J.H. Mullahy Endowment in Environmental Biology, and the Academy of Finland decision \# 266523 to TMR. We thank T. Atunes, A. Barkley, B. Burnet, B. Carneiro Alves, S. Gergen, M. Grabner, D. Hackenburg, S. Hartikainen, G. LeBleu and P. Pouta for their assistance. This chapter is dedicated to the memory of Ronald J. Ryel who died from complications arising from pancreatic cancer in November 2015 and who was instrumental in providing direction and expertise for a substantial amount of the research described here. 


\subsection{References}

Agati, G., Azzarello, E., Pollastri, S. \& Tattini, M. 2012. Flavonoids as antioxidants in plants: Location and functional significance. Plant Science, 196, 67-76.

Agati, G., Cerovic, Z. G., Dalla Marta, A., Di Stefano, V., Pinelli, P., Traversi, M. L. \& Orlandini, S. 2008. Optically-assessed preformed flavonoids and susceptibility of grapevine to Plasmopara viticola under different light regimes. Functional Plant Biology, 35, 77-84.

Agati, G., Cerovic, Z. G., Pinelli, P. \& Tattini, M. 2011. Light-induced accumulation of ortho-dihydroxylated flavonoids as non-destructively monitored by chlorophyll fluorescence excitation techniques. Environmental and Experimental Botany, 73, 3-9.

Albert, A., Sareedenchai, V., Heller, W., Seidlitz, H. K. \& Zidorn, C. 2009. Temperature is the key to altitudinal variation of phenolics in Arnica montana L. cv. ARBO. Oecologia, 160, 1-8.

Aphalo, P. J. 2017. Chapter 2. UV-B measurement and methodology. In: JORDAN, B. $\mathrm{R}$. (ed.) The role of $U V-B$ radiation in plant growth and development. Oxford, UK: CABI Press.

Atamian, H. S., Creux, N. M., Brown, E. A., Garner, A. G., Blackman, B. K. \& Harmer, S. L. 2016. Circadian regulation of sunflower heliotropism, floral orientation, and pollinator visits. Science, 353, 587-590.

Bais, A. F., Mckenzie, R. L., Bernhard, G., Aucamp, P. J., Ilyas, M., Madronich, S. \& Tourpali, K. 2015. Ozone depletion and climate change: impacts on UV radiation. Photochemical \& Photobiological Sciences, 14, 19-52. 
Ballaré, C. L. \& Austin, A. T. 2017. Chapter 3. A perspective on UV-B and terrestrial ecosystems. In: JORDAN, B. R. (ed.) The role of $U V$-B radiation in plant growth and development. Oxford, UK: CABI Press.

Ballaré, C. L., Caldwell, M. M., Flint, S. D., Robinson, S. A. \& Bornman, J. F. 2011. Effects of solar ultraviolet radiation on terrestrial ecosystems. Patterns, mechanisms, and interactions with climate change. Photochemical \& Photobiological Sciences, 10, 226-241.

Bandurska, H., Niedziela, J. \& Chadzinikolau, T. 2013. Separate and combined responses to water deficit and UV-B radiation. Plant Science 213, 98-105.

Barnes, P. W., Flint, S. D., Ryel, R. J., Tobler, M. A., Barkley, A. E. \& Wargent, J. J. 2015. Rediscovering leaf optical properties: New insights into plant acclimation to solar UV radiation. Plant Physiology and Biochemistry, 93, 94-100.

Barnes, P. W., Flint, S. D., Slusser, J. R., Gao, W. \& Ryel, R. J. 2008. Diurnal changes in epidermal UV transmittance of plants in naturally high UV environments. Physiologia Plantarum, 133, 363-372.

Barnes, P. W., Flint, S. D., Tobler, M. A. \& Ryel, R. J. 2016a. Diurnal adjustment in UVsunscreen protection is widespread among higher plants. Oecologia, 181, 55-63.

Barnes, P. W., Kersting, A. R., Flint, S. D., Beyschlag, W. \& Ryel, R. J. 2013. Adjustments in epidermal UV-transmittance of leaves in sun-shade transitions. Physiologia Plantarum, 149, 200-213.

Barnes, P. W., Searles, P. S., Ballaré, C. L., Ryel, R. J. \& Caldwell, M. M. 2000. Noninvasive measurements of leaf epidermal transmittance of UV radiation using 
chlorophyll fluorescence: field and laboratory studies. Physiologia Plantarum, $109,274-283$.

Barnes, P. W., Tobler, M. A., Keefover-Ring, K., Flint, S. D., Barkley, A. E., Ryel, R. J. \& Lindroth, R. L. 2016b. Rapid modulation of ultraviolet shielding in plants is influenced by solar ultraviolet radiation and linked to alterations in flavonoids. Plant Cell \& Environment, 39, 222-230.

Bidel, L. P. R., Chomicki, G., Bonini, F., Mondolot, L., Soulé, J., Coumans, M., La Fisca, P., Baissac, Y., Petit, V., Loiseau, A., Cerovic, Z. G., Gould, K. S. \& JayAllemand, C. 2015. Dynamics of flavonol accumulation in leaf tissues under different UV-B regimes in Centella asiatica (Apiaceae). Planta, 242, 545-559.

Bidel, L. P. R., Meyer, S., Goulas, Y., Cadot, Y. \& Cerovic, Z. G. 2007. Responses of epidermal phenolic compounds to light acclimation: In vivo qualitative and quantitative assessment using chlorophyll fluorescence excitation spectra in leaves of three woody species. Journal of Photochemistry and Photobiology BBiology, 88, 163-179.

Bilger, W., Rolland, M. \& Nybakken, L. 2007. UV screening in higher plants induced by low temperature in the absence of UV-B radiation. Photochemical \& Photobiological Sciences, 6, 190-195.

Björn, L. O. 2015. On the history of phyto-photo UV science (not to be left in skoto toto and silence). Plant Physiology and Biochemistry, 93, 3-8.

Bornman, J. F. 2017. Chapter 1. An introduction to UV-B as an environmental parameter. In: JORDAN, B. F. (ed.) The role of $U V$-B in plant growth and development. Oxford, UK: CABI Press. 
Bornman, J. F., Barnes, P. W., Robinson, S. A., Ballaré, C. L., Flint, S. D. \& Caldwell, M. M. 2015. Solar ultraviolet radiation and ozone depletion-driven climate change: effects on terrestrial ecosystems. Photochemical \& Photobiological Sciences, 14, 88-107.

Boulton, R. 2001. The copigmentation of anthocyanins and its role in the color of red wine: a critical review. American Journal of Enology and Viticulture, 52, 67-87.

Britt, A. B. 1999. Molecular genetics of DNA repair in higher plants. Trends in Plant Science, 4, 20-25.

Burchard, P., Bilger, W. \& Weissenböck, G. 2000. Contribution of hydroxycinnamates and flavonoids to epidermal shielding of UV-A and UV-B radiation in developing rye primary leaves as assessed by ultraviolet-induced chlorophyll fluorescence measurements. Plant Cell \& Environment, 23, 1373-1380.

Caldwell, M. M. 1971. Solar UV irradiation and the growth and development of higher plants. Photophysiology, 6, 131-177.

Caldwell, M. M. \& Flint, S. D. 1994. Stratospheric ozone reduction, solar UV-B radiation and terrestrial ecosystems. Climatic Change, 28, 375-394.

Caldwell, M. M., Robberecht, R. \& Flint, S. D. 1983. Internal filters: Prospects for UVacclimation in higher plants. Physiologia Plantarum, 58, 445-450.

Day, T. A., Howells, B. W. \& Rice, W. J. 1994. Ultraviolet absorption and epidermaltransmittance spectra in foliage. Physiologia Plantarium, 92, 207-218.

Day, T. A., Vogelmann, T. C. \& Delucia, E. H. 1992. Are some plant life forms more effective than others in screening out ultraviolet-B radiation? Oecologia, 92, 513519. 
Dean, J. C., Kusaka, R., Walsh, P. S., Allais, F. \& Zwier, T. S. 2014. Plant Sunscreens in the UV-B: Ultraviolet Spectroscopy of Jet-Cooled Sinapoyl Malate, Sinapic Acid, and Sinapate Ester Derivatives. Journal of the American Chemical Society, 136, 14780-95.

Demkura, P. V. \& Ballaré, C. L. 2012. UVR8 Mediates UV-B-induced Arabidopsis defense responses against Botrytis cinerea by controlling sinapate accumulation. Molecular Plant, 5, 642-652.

Emiliani, J., Grotewold, E., Falcone Ferreyra, M. L. \& Casati, P. 2013. Flavonols protect Arabidopsis plants against UV-B deleterious effects. Molecular Plant, 6, 13761379.

Favory, J. J., Stec, A., Gruber, H., Rizzini, L., Oravecz, A., Funk, M., Albert, A., Cloix, C., Jenkins, G. I., Oakeley, E. J., Seidlitz, H. K., Nagy, F. \& Ulm, R. 2009. Interaction of COP1 and UVR8 regulates UV-B-induced photomorphogenesis and stress acclimation in Arabidopsis. Embo Journal, 28, 591-601.

Feher, B., Kozma-Bognar, L., Kevei, E., Hajdu, A., Binkert, M., Davis, S. J., Schafer, E., Ulm, R. \& Nagy, F. 2011. Functional interaction of the circadian clock and UV RESISTANCE LOCUS 8-controlled UV-B signaling pathways in Arabidopsis thaliana. Plant Journal, 67, 37-48.

Fischbach, R. J., Kossmann, B., Panten, H., Steinbrecher, R., Heller, W., Seidlitz, H. K., Sandermann, H., Hertkorn, N. \& Schnitzler, J. P. 1999. Seasonal accumulation of ultraviolet-B screening pigments in needles of Norway spruce (Picea abies ( L.) Karst.). Plant Cell \& Environment, 22, 27-37. 
Flint, S. D. \& Caldwell, M. M. 1998. Solar UV-B and visible radiation in tropical forest gaps: measurements partitioning direct and diffuse radiation. Global Change Biology, 4, 863-870.

Flint, S. D., Searles, P. S. \& Caldwell, M. M. 2004. Field testing of biological spectral weighting functions for induction of UV-absorbing compounds in higher plants. Photochemistry and Photobiology, 79, 399-403.

Goodspeed, D., Chehab, E. W., Min-Venditti, A., Braam, J. \& Covington, M. F. 2012. Arabidopsis synchronizes jasmonate-mediated defense with insect circadian behavior. Proceedings of the National Academy of Sciences of the United States of America, 109, 4674-4677.

Götz, M., Albert, A., Stich, S., Heller, W., Scherb, H., Krins, A., Langebartels, C., Seidlitz, H. K. \& Ernst, D. 2010. PAR modulation of the UV-dependent levels of flavonoid metabolites in Arabidopsis thaliana (L.) Heynh. leaf rosettes: cumulative effects after a whole vegetative growth period. Protoplasma, 243, 95103.

Goulas, Y., Cerovic, Z. G., Cartelat, A. \& Moya, I. 2004. Dualex: a new instrument for field measurements of epidermal ultraviolet absorbance by chlorophyll fluorescence. Applied Optics, 43, 4488-4496.

Guidi, L., Degl'innocenti, E., Remorini, D., Biricolti, S., Fini, A., Ferrini, F., Nicese, F. P. \& Tattini, M. 2011. The impact of UV-radiation on the physiology and biochemistry of Ligustrum vulgare exposed to different visible-light irradiance. Environmental and Experimental Botany, 70, 88-95. 
Hectors, K., Prinsen, E., Van Oevelen, S., Guisez, Y. \& Jansen, M. 2009. Interactions between two UV-B protective responses: Morphogenesis and UV screening. Comparative Biochemistry and Physiology a-Molecular \& Integrative Physiology, 153A, S202-S202.

Hectors, K., Van Oevelen, S., Geuns, J., Guisez, Y., Jansen, M. a. K. \& Prinsen, E. 2014. Dynamic changes in plant secondary metabolites during UV acclimation in Arabidopsis thaliana. Physiologia Plantarum, 152, 219-230.

Hectors, K., Van Oevelen, S., Guisez, Y., Prinsen, E. \& Jansen, M. a. K. 2012. The phytohormone auxin is a component of the regulatory system that controls UVmediated accumulation of flavonoids and UV-induced morphogenesis. Physiologia Plantarum, 145, 594-603.

Heisler, G. M., Grant, R. H. \& Gao, W. 2003. Individual- and scattered-tree influences on ultraviolet irradiance. Agricultural and Forest Meteorology, 120, 113-126.

Hofmann, R. W. \& Jahufer, M. Z. Z. 2011. Tradeoff between biomass and flavonoid accumulation in white clover reflects contrasting plant strategies. Plos One, 6.

Izaguirre, M. M., Mazza, C. A., Svatos, A., Baldwin, I. T. \& Ballaré, C. L. 2007. Solar ultraviolet-B radiation and insect herbivory trigger partially overlapping phenolic responses in Nicotiana attenuata and Nicotiana longiflora. Annals of Botany, 99, 103-109.

Jacques, E., Hectors, K., Guisez, Y., Verbelen, J. P., Vissenberg, K., Prinsen, E. \& Jansen, M. 2009. Leaf and cell development during UV-B acclimation in Arabidopsis thaliana. Comparative Biochemistry and Physiology a-Molecular \& Integrative Physiology, 153A, S203-S203. 
Jansen, M. a. K. \& Bornman, J. F. 2012. UV-B radiation: from generic stressor to specific regulator. Physiologia Plantarum, 145, 501-504.

Jenkins, G. I. 2014. The UV-B Photoreceptor UVR8: From Structure to Physiology. Plant Cell, 26, 21-37.

Jenkins, G. I. 2017. Chapter 9. Isolation and characterization of UVR8. In: JORDAN, B. $\mathrm{R}$. (ed.) The role of $U V-B$ radiation in plant growth and development. Oxford, UK: CABI Press.

Kaiserli, E. \& Jenkins, G. I. 2007. UV-B promotes rapid nuclear translocation of the Arabidopsis UV-B-specific signaling component UVR8 and activates its function in the nucleus. Plant Cell, 19, 2662-2673.

Kim, S.-G., Yon, F., Gaquerel, E., Gulati, J. \& Baldwin, I. T. 2011. Tissue specific diurnal rhythms of metabolites and their regulation during herbivore attack in a native Tobacco, Nicotiana attenuata. Plos One, 6, 1-13.

Kolb, C. A., Kaser, M. A., Kopecky, J., Zotz, G., Riederer, M. \& Pfündel, E. E. 2001. Effects of natural intensities of visible and ultraviolet radiation on epidermal ultraviolet screening and photosynthesis in grape leaves. Plant Physiology, 127, 863-875.

Kolb, C. A., Schreiber, U., Gademann, R. \& Pfündel, E. E. 2005. UV-A screening in plants determined using a new portable fluorimeter. Photosynthetica, 43, 371-377.

König, S., Feussner, K., Kaever, A., Landesfeind, M., Thurow, C., Karlovsky, P., Gatz, C., Polle, A. \& Feussner, I. 2014. Soluble phenylpropanoids are involved in the defense response of Arabidopsis against Verticillium longisporum. New Phytologist, 202, 823-837. 
Kotilainen, T., Tegelberg, R., Julkunen-Tiitto, R., Lindfors, A., O'hara, R. B. \& Aphalo, P. J. 2010. Seasonal fluctuations in leaf phenolic composition under UV manipulations reflect contrasting strategies of alder and birch trees. Physiologia Plantarum, 140, 297-309.

Krause, G. H., Galle, A., Gademann, R. \& Winter, K. 2003a. Capacity of protection against ultraviolet radiation in sun and shade leaves of tropical forest plants. Functional Plant Biology, 30, 533-542.

Krause, G. H., Grube, E., Koroleva, O. Y., Barth, C. \& Winter, K. 2004. Do mature shade leaves of tropical tree seedlings acclimate to high sunlight and UV radiation? Functional Plant Biology, 31, 743-756.

Krause, G. H., Grube, E., Virgo, A. \& Winter, K. 2003b. Sudden exposure to solar UV-B radiation reduces net $\mathrm{CO} 2$ uptake and photosystem I efficiency in shadeacclimated tropical tree seedlings. Plant Physiology, 131, 745-752.

Krause, G. H., Jahns, P., Virgo, A., Garcia, M., Aranda, J., Wellmann, E. \& Winter, K. 2007. Photoprotection, photosynthesis and growth of tropical tree seedlings under near-ambient and strongly reduced solar ultraviolet-B radiation. Journal of Plant Physiology, 164, 1311-1322.

Kuhlmann, F. \& Müller, C. 2010. UV-B impact on aphid performance mediated by plant quality and plant changes induced by aphids. Plant Biology, 12, 676-684.

Kuhn, B. M., Geisler, M., Bigler, L. \& Ringli, C. 2011. Flavonols accumulate asymmetrically and affect auxin transport in Arabidopsis. Plant Physiology, 156, $585-595$. 
Lautenschlager-Fleury, D. 1955. Über die Ultraviolettdurchläessigkeit von Blattepidermen. Berichte Schweiz Botanischen Gesellschaft, 65, 343-386.

Li, J., Yang, L., Jin, D., Nezames, C. D., Terzaghi, W. \& Deng, X. W. 2013. UV-Binduced photomorphogenesis in Arabidopsis. Protein \& Cell, 4, 485-492.

Liakoura, V., Manetas, Y. \& Karabourniotis, G. 2001. Seasonal fluctuations in the concentration of UV-absorbing compounds in the leaves of some Mediterranean plants under field conditions. Physiologia Plantarum, 111, 491-500.

Lopez, M. L., Palancar, G. G. \& Toselli, B. M. 2009. Effect of different types of clouds on surface UV-B and total solar irradiance at southern mid-latitudes: CMF determinations at Cordoba, Argentina. Atmospheric Environment, 43, 3130-3136.

Louis, J., Meyer, S., Maunoury-Danger, F., Fresneau, C., Meudec, E. \& Cerovic, Z. G. 2009. Seasonal changes in optically assessed epidermal phenolic compounds and chlorophyll contents in leaves of sessile oak (Quercus petraea): towards signatures of phenological stage. Functional Plant Biology, 36, 732-741.

Madronich, S., Wagner, M. \& Groth, P. 2011. Influence of tropospheric ozone control on exposure to ultraviolet radiation at the surface. Environmental Science \& Technology, 45, 6919-6923.

Mazza, C. A. \& Ballaré, C. L. 2015. Photoreceptors UVR8 and phytochrome B cooperate to optimize plant growth and defense in patchy canopies. New Phytologist, 207, 49.

Mazza, C. A., Boccalandro, H. E., Giordano, C. V., Battista, D., Scopel, A. L. \& Ballaré, C. L. 2000. Functional significance and induction by solar radiation of ultraviolet- 
absorbing sunscreens in field-grown soybean crops. Plant Physiology, 122, 117125.

Mcclung, C. R. 2001. Circadian rhythms in plants. Annual Review of Plant Physiology and Plant Molecular Biology, 52, 139-162.

Mewis, I., Schreiner, M., Chau Nhi, N., Krumbein, A., Ulrichs, C., Lohse, M. \& Zrenner, R. 2012. UV-B irradiation changes specifically the secondary metabolite profile in broccoli sprouts: Induced signaling overlaps with defense response to biotic stressors. Plant and Cell Physiology, 53, 1546-1560.

Morales, L. O., Brosché, M., Vainonen, J., Jenkins, G. I., Wargent, J. J., Sipari, N., Strid, A., Lindfors, A. V., Tegelberg, R. \& Aphalo, P. J. 2013. Multiple roles for UV RESISTANCE LOCUS8 in regulating gene expression and metabolite accumulation in Arabidopsis under solar ultraviolet radiation. Plant Physiology, 161, 744-759.

Morales, L. O., Tegelberg, R., Brosché, M., Lindfors, A., Siipola, S. \& Aphalo, P. J. 2011. Temporal variation in epidermal flavonoids due to altered solar UV radiation is moderated by the leaf position in Betula pendula. Physiologia Plantarum, 143, 261-270.

Nenadis, N., Llorens, L., Koufogianni, A., Diaz, L., Font, J., Abel Gonzalez, J. \& Verdaguer, D. 2015. Interactive effects of UV radiation and reduced precipitation on the seasonal leaf phenolic content/composition and the antioxidant activity of naturally growing Arbutus unedo plants. Journal of Photochemistry and Photobiology B-Biology, 153, 435-444. 
Neugart, S., Fiol, M., Schreiner, M., Rohn, S., Zrenner, R., Kroh, L. W. \& Krumbein, A. 2013. Low and moderate photosynthetically active radiation affects the flavonol glycosides and hydroxycinnamic acid derivatives in kale (Brassica oleracea var. sabellica) dependent on two low temperatures. Plant Physiology and Biochemistry, 72, 161-168.

Neugart, S., Zietz, M., Schreiner, M., Rohn, S., Kroh, L. W. \& Krumbein, A. 2012. Structurally different flavonol glycosides and hydroxycinnamic acid derivatives respond differently to moderate UV-B radiation exposure. Physiologia Plantarum, 145, 582-593.

Nybakken, L., Aubert, S. \& Bilger, W. 2004a. Epidermal UV-screening of arctic and alpine plants along a latitudinal gradient in Europe. Polar Biology, 27, 391-398.

Nybakken, L., Bilger, W., Johanson, U., Björn, L. O., Zielke, M. \& Solheim, B. 2004b. Epidermal UV-screening in vascular plants from Svalbard (Norwegian Arctic). Polar Biology, 27, 383-390.

Parisi, A. V. \& Kimlin, M. G. 1999. Comparison of spectral biologically effective solar ultraviolet in adjacent tree and sun. Physics in Medicine and Biology, 44, 20712080.

Peter, H. J., Krüger-Alef, C., Knogge, W., Brinkmann, K. \& Weissenböck, G. 1991. Diurnal periodicity of chalcone-synthase activity during the development of oat primary leaves. Planta, 183, 409-15.

Pollastrini, M., Di Stefano, V., Ferretti, M., Agati, G., Grifoni, D., Zipoli, G., Orlandini, S. \& Bussotti, F. 2011. Influence of different light intensity regimes on leaf 
features of Vitis vinifera L. in ultraviolet radiation filtered condition. Environmental and Experimental Botany, 73, 108-115.

Qi, Y., Heisler, G. M., Gao, W., Vogelmann, T. C. \& Bai, S. 2010. Characteristics of UV-B radiation tolerance in broadleaf trees in southern USA. In: GAO, W., SCHMOLDT, D. L. \& SLUSSER, J. R. (eds.) UV radiation in global climate change. Measurements, modeling and effects on ecosystems. Berlin: SpringerVerlag.

Randriamanana, T. R., Nissinen, K., Moilanen, J., Nybakken, L. \& Julkunen-Tiitio, R. 2015. Long-term UV-B and temperature enhancements suggest that females of Salix myrsinifolia plants are more tolerant to UV-B than males. Environmental and Experimental Botany, 109, 296-305.

Ringli, C., Bigler, L., Kuhn, B. M., Leiber, R. M., Diet, A., Santelia, D., Frey, B., Pollmann, S. \& Klein, M. 2008. The modified flavonol glycosylation profile in the Arabidopsis rol 1 mutants results in alterations in plant growth and cell shape formation. Plant Cell, 20, 1470-1481.

Rizzini, L., Favory, J.-J., Cloix, C., Faggionato, D., O'hara, A., Kaiserli, E., Baumeister, R., Schaefer, E., Nagy, F., Jenkins, G. I. \& Ulm, R. 2011. Perception of UV-B by the Arabidopsis UVR8 protein. Science, 332, 103-106.

Robson, T. M., Klem, K., Urban, O. \& Jansen, M. a. K. 2015. Re-interpreting plant morphological responses to UV-B radiation. Plant, Cell \& Environment, 38, 856866.

Schnitzler, J. P., Jungblut, T. P., Heller, W., Kofferlein, M., Hutzler, P., Heinzmann, U., Schmelzer, E., Ernst, D., Langebartels, C. \& Sandermann, H. 1996. Tissue 
localization of uv-B-screening pigments and of chalcone synthase mRNA in needles of Scots pine seedlings. New Phytologist, 132, 247-258.

Schreiner, M., Mewis, I., Huyskens-Keil, S., Jansen, M. a. K., Zrenner, R., Winkler, J. B., O'brien, N. \& Krumbein, A. 2012. UV-B-induced secondary plant metabolites potential benefits for plant and human health. Critical Reviews in Plant Sciences, $31,229-240$.

Schreiner, M., Neugart, S., Wiesner, M. \& Baldermann, S. 2017. Chapter 4. Plant defence against UV-B. In: JORDAN, B. R. (ed.) The role of UV-B radiation in plant growth and development. Oxford, UK: CABI Press.

Searles, P. S., Flint, S. D. \& Caldwell, M. M. 2001. A meta-analysis of plant field studies simulating stratospheric ozone depletion. Oecologia, 127, 1-10.

Siipola, S. M., Kotilainen, T., Sipari, N., Morales, L. O., Lindfors, A. V., Robson, T. M. \& Aphalo, P. J. 2015. Epidermal UV-A absorbance and whole-leaf flavonoid composition in pea respond more to solar blue light than to solar UV radiation. Plant, Cell \& Environment, 38, 941-952.

Snell, K. R. S., Kokubun, T., Griffiths, H., Convey, P., Hodgson, D. A. \& Newsham, K. K. 2009. Quantifying the metabolic cost to an Antarctic liverwort of responding to an abrupt increase in UVB radiation exposure. Global Change Biology, 15, 25632573.

Strid, A. \& Hideg, E. 2017. Chapter 7. The effects of UV-B on the biochemistry and metabolism of plants. In: JORDAN, B. R. (ed.) The role of $U V$-B radiation in plant growth and development. Oxford, UK: CABI Press. 
Sullivan, J. H., Gitz, D. C., Liu-Gitz, L., Xu, C. P., Gao, W. \& Slusser, J. 2007. Coupling short-term changes in ambient UV-B levels with induction of UV-screening compounds. Photochemistry and Photobiology, 83, 863-870.

Thiel, S., Steiner, K. \& Seidlitz, H. K. 1997. Modification of global erythemally effective irradiance by clouds. Photochemistry and Photobiology, 65, 969-973.

Tilbrook, K., Arongaus, A. B., Binkert, M., Heijde, M., Yin, R. \& Ulm, R. 2013. The UVR8 UV-B Photoreceptor: Perception, Signaling and Response. The Arabidopsis book/American Society of Plant Biologists, 11, e0164-e0164.

Turnbull, T. L., Barlow, A. M. \& Adams, M. A. 2013. Photosynthetic benefits of ultraviolet-A to Pimelea ligustrina, a woody shrub of sub-alpine Australia. Oecologia, 173, 375-385.

Veit, M., Bilger, T., Muhlbauer, T., Brummet, W. \& Winter, K. 1996. Diurnal changes in flavonoids. Journal of Plant Physiology, 148, 478-482.

Wargent, J. J. 2017. Chapter 11. Turning UV-B photobiology into commercial reality. In: JORDAN, B. R. (ed.) The role of $U V-B$ radiation in plant growth and development. Oxford, UK: CABI Press.

Wargent, J. J., Elfadly, E. M., Moore, J. P. \& Paul, N. D. 2011. Increased exposure to UV-B radiation during early development leads to enhanced photoprotection and improved long-term performance in Lactuca sativa. Plant, Cell \& Environment, 34, 1401-1413.

Wargent, J. J. \& Jordan, B. R. 2013. From ozone depletion to agriculture: understanding the role of UV radiation in sustainable crop production. New Phytologist, 197, 1058-1076. 
Wargent, J. J., Nelson, B. C. W., Mcghie, T. K. \& Barnes, P. W. 2015. Acclimation to UV-B radiation and visible light in Lactuca sativa involves up-regulation of photosynthetic performance and orchestration of metabolome-wide responses. Plant, Cell \& Environment, 38, 929-940.

Williamson, C. E., Zepp, R. G., Lucas, R. M., Madronich, S., Austin, A. T., Ballare, C. L., Norval, M., Sulzberger, B., Bais, A. F., Mckenzie, R. L., Robinson, S. A., Haeder, D.-P., Paul, N. D. \& Bornman, J. F. 2014. Solar ultraviolet radiation in a changing climate. Nature Climate Change, 4, 434-441.

Xie, L. \& Hauser, M.-T. 2012. Induction of ARI12 upon broad band UV-B radiation is suppressed by UVR8 and cryptochromes. Plant Signaling \& Behavior, 7, 1411-4.

Zavala, J. A., Mazza, C. A., Dillon, F. M., Chludil, H. D. \& Ballaré, C. L. 2015. Soybean resistance to stink bugs (Nezara viridula and Piezodorus guildinii) increases with exposure to solar UV-B radiation and correlates with isoflavonoid content in pods under field conditions. Plant, Cell \& Environment, 38, 920-928. 
Figure 6.1. Variability in ultraviolet-B irradiance at multiple time scales. Panel A shows integrated daily plant effective UV-B over three years at a Sonoran Desert location in southern Arizona, USA, with the annual summer monsoon period noted. Panel B shows daily plant effective UV-B at Pullman, Washington, USA over a period in early spring (April-early May 2014) when new leaves are emerging in many native plant species. Panel C show diurnal patterns of plant effective UV-B (30 min means) under clear and cloudy sky conditions in the Arizona Sonoran Desert in July 2015. Panel D shows instantaneous UV-B at the same location (to the nearest $\mathrm{cm}$ ) in the understory of a 20year old Betula pendula stand in a provenance trial at Little Wittenham, Oxfordshire, UK, on a windy and relatively calm day. All irradiance data are weighted according to the generalize plant action spectrum (Caldwell, 1971) and normalized to unity at $300 \mathrm{~nm}$. Data in A and C were obtained from an on-site broad-band UV-B sensor (YES UVB-1) calibrated against a double-monochromator spectroradiometer (Optronics 756). Data in B were obtained from the USDA UV monitoring network (http://uvb.nrel.colostate.edu/UVB/index.jsf) using data from narrow waveband spectrometers to produce synthetic spectra. Data in D were obtained from a diode array spectroradiometer (OceanOptics Maya Pro2000+) measuring spectral irradiance every 0.1 seconds for a 10 second period.

Figure 6.2. Illustration of a typical dicot leaf showing the penetration of PAR (400-700 $\mathrm{nm})$ and UV (280-400 $\mathrm{nm}$ ) radiation through the epidermal tissue. The majority (ca. 90\% of the incident UV is absorbed by flavonoids and other UV-absorbing compounds in the epidermis while most of the PAR is transmitted to the underlying mesophyll where 
photosynthesis occurs. The epidermal UV transmittance (TUV) of the epidermis varies over time in relation to the stage of leaf development, UV and PAR exposure and, in some species, time of season, day and cloud cover.

Figure 6.3. The response of adaxial epidermal UV transmittance $\left(\mathrm{T}_{\mathrm{UV}}\right.$; measured with a UVA-PAM) to different light environments in pot-grown Arabidopsis thaliana (Panel A) and field-grown Populus tremuloides (aspen; Panels B, C). Panel A shows the time course of Tuv in A. thaliana grown in a growth chamber with no UV-B and then transferred to different conditions (indoor and outdoors) that differed in levels of UV-B (as measured with a calibrated broad band UV-B sensor). Inset shows the relationship between TUv measured 5 days after transfer and relative UV irradiances. Panel B shows the relationship between adaxial $\mathrm{T}_{\mathrm{UV}}$ and midday photon flux density (PFD) of PAR (400-700 nm) in P. tremuloides leaves occupying different canopy environments. Panel $\mathrm{C}$ shows the response of $\mathrm{T}_{\mathrm{UV}}$ in sun and shade leaves of $P$. tremuloides subjected to different solar radiation treatments in the field. Data are means \pm SE. Panel A is from an unpublished study by T. Atunes, M. Tobler, and P. Barnes; Panels B and C are reproduced from Barnes et al. (2013).

Figure 6.4. The absorbance of UV at $375 \mathrm{~nm}$ by leaf upper epidermal flavonoids (AU) in Centaurea uniflora as measured using chlorophyll fluorescence (Dualex Scientific+, Force-A, Paris). Measurements were taken on plants growing in a subalpine meadow (2130 $\mathrm{m}$ asl) in the French Alps during July 2015. Cylindrical filters (220 mm diameter $\times 300 \mathrm{~mm}$ height) made from special plastic films that completely attenuated either UV- 
B radiation (polyester, $0.125 \mathrm{~mm}$ thick, Autostat CT5; Thermoplast, Helsinki, Finland); UV-A and UV-B radiation (Rosco \#226 supergel, Westlighting, Helsinki, Finland); or blue, UV-A and UV-B radiation (Rosco $312 \underline{z}$ Canary Yellow) provided the filtration treatments, and were compared to a full-spectrum control (polyethene, $0.05 \mathrm{~mm}$ thick, 04 PE-LD; Etola, Jyväskylä, Finland) and a control in complete darkness (polyethene, solid white outside, solid black inside). Data are means \pm SE change in absorbance of each leaf from its initial value $\left(\mathrm{n}=5\right.$ per filter type). ${ }^{*}=$ means within a filter treatment significantly different at $P<0.05$ based on ANOVA (T.M. Robson and S.M. Hartikainen, unpubl. data).

Figure 6.5. Diurnal change in adaxial epidermal UV transmittance (TUV; measured with a UVA-PAM) in Abelmoschus esculentus (okra; Panel A) and calculated plant effective UV-B irradiance directly beneath the epidermis (Panel B) under near-clear summer sky conditions in New Orleans, Louisiana, USA. TUv data in Panel A are means \pm SE. Panel B shows the diurnal course of calculated UV-B irradiance just beneath the adaxial (upper) epidermis for three scenarios: measured diurnal change in $\mathrm{T}_{\mathrm{UV}}$ (circles), assuming constant dawn epidermal Tuv (squares) and assuming constant midday Tuv (triangles). Calculations assumed a horizontal leaf and no qualitative change in the UV-absorbance spectrum (Reproduced from Barnes et al. 2015).

Figure 6.6. Diurnal change (predawn to midday) in adaxial epidermal UV transmittance (TUv; measured with a UVA-PAM) in pot-grown Capsicum annuum (pepper) and Abelmoschus esculentus (okra; Panel A) and midday $\mathrm{T}_{\mathrm{Uv}}$ in these species grown under 
ambient (+UV) and attenuated (-UV) solar UV (280-400 nm) in New Orleans, Louisiana, USA (Panel B). Data are means $\pm \operatorname{SE~}(n=24) . * *=$ means within a species significantly different at $P<0.01$ based on ANOVA (I. Bottger, M. Tobler and P. Barnes, unpublished data). 
Fig 6.1
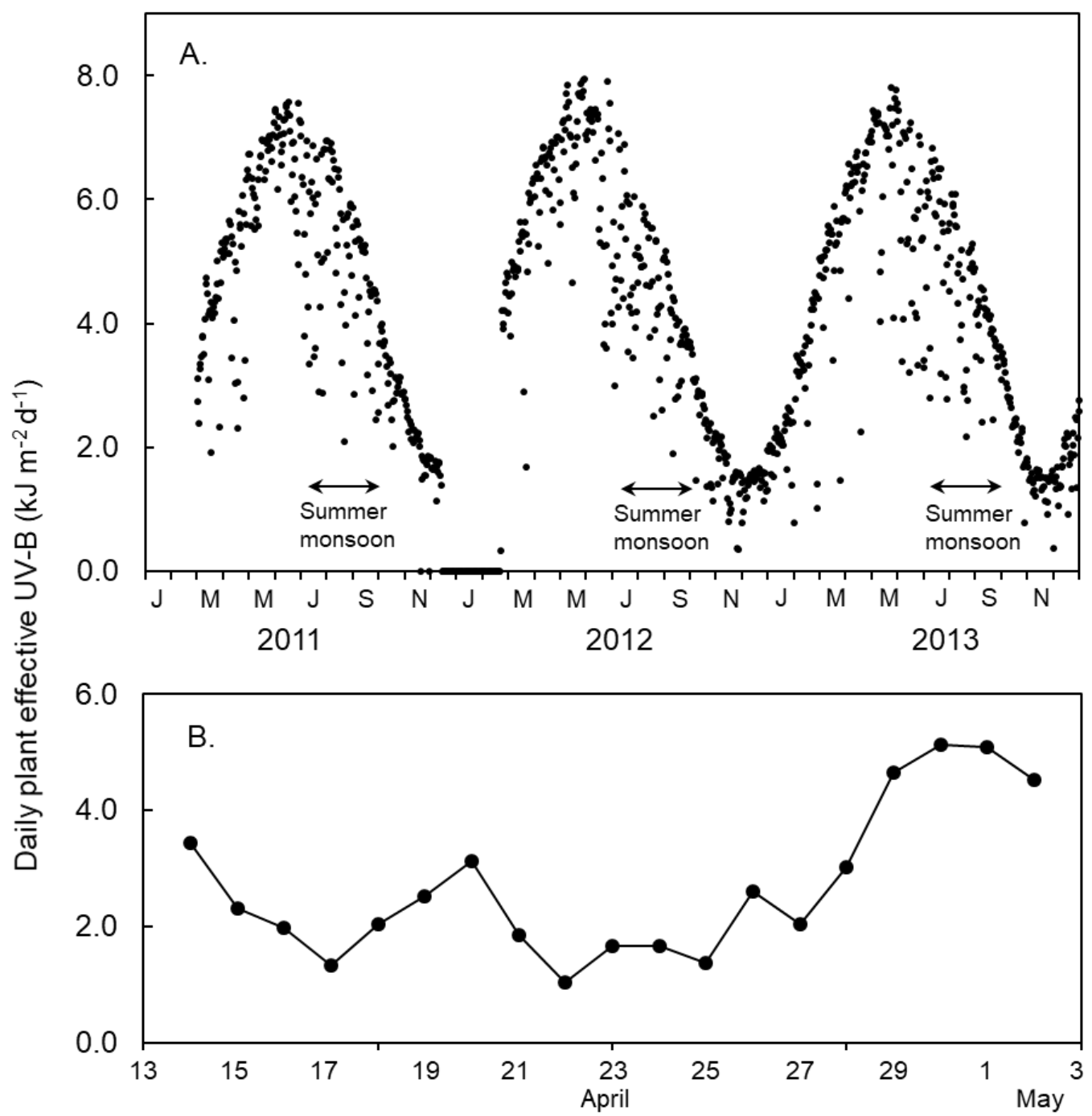

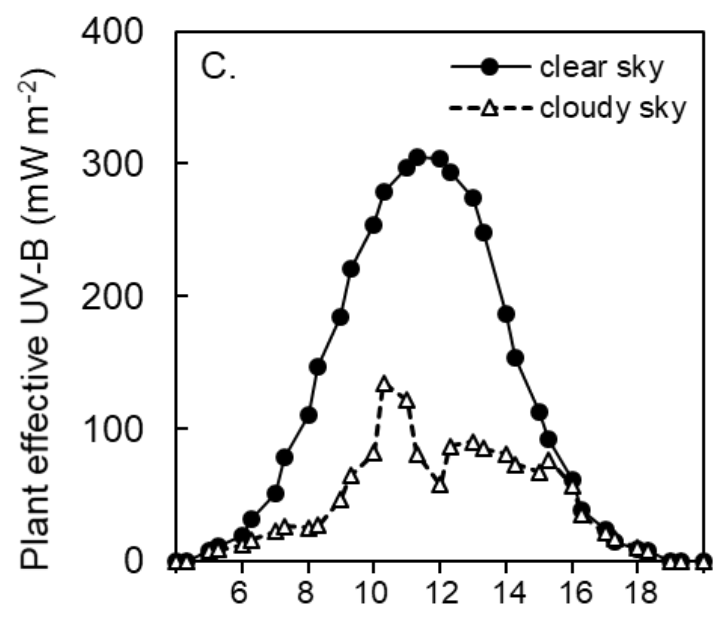

Hour of day (MST)

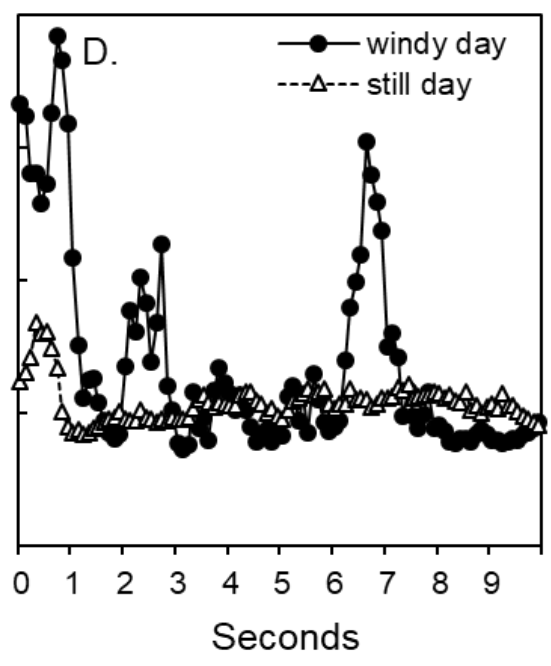


Fig 6.2

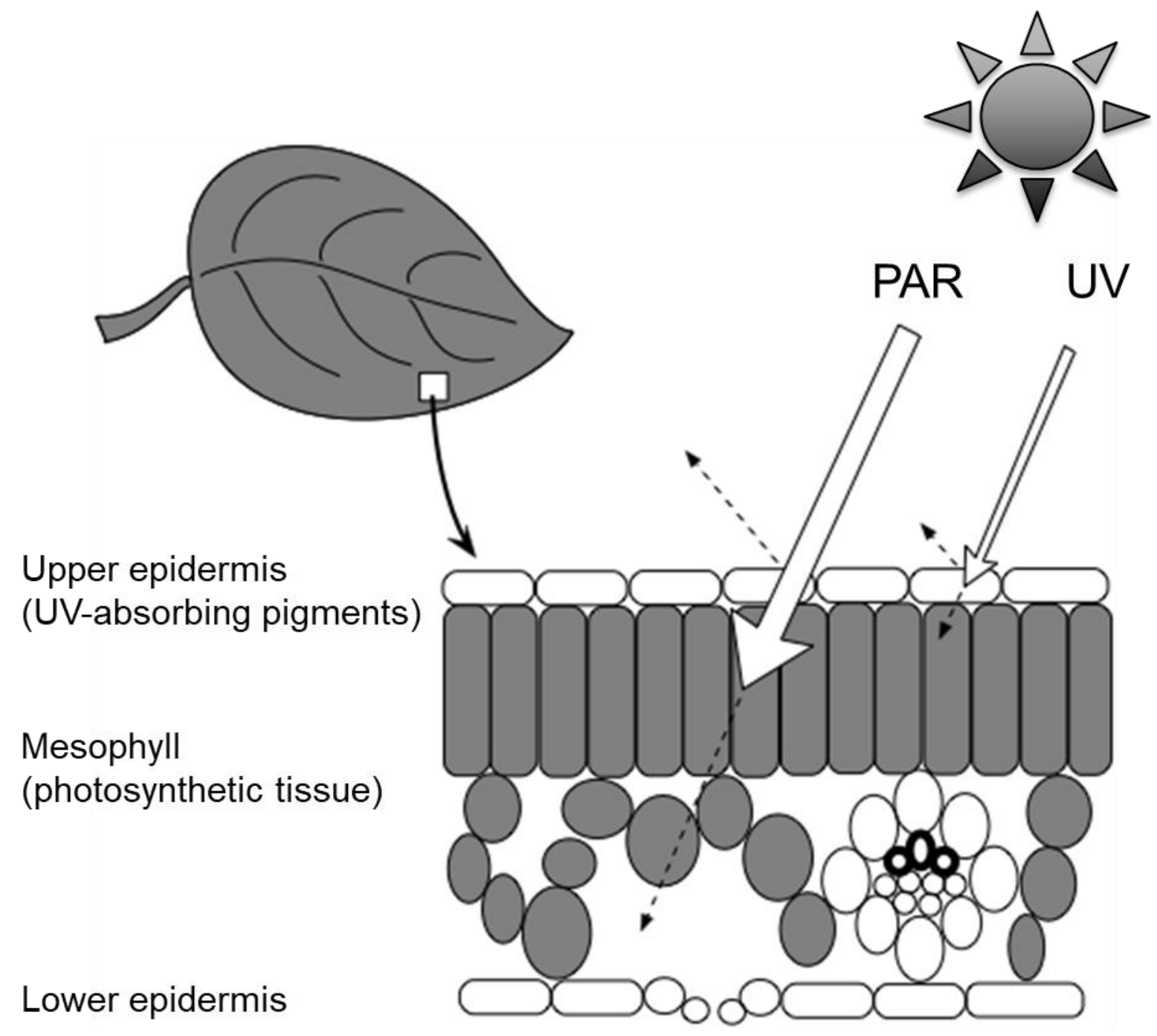


Fig. 6.3
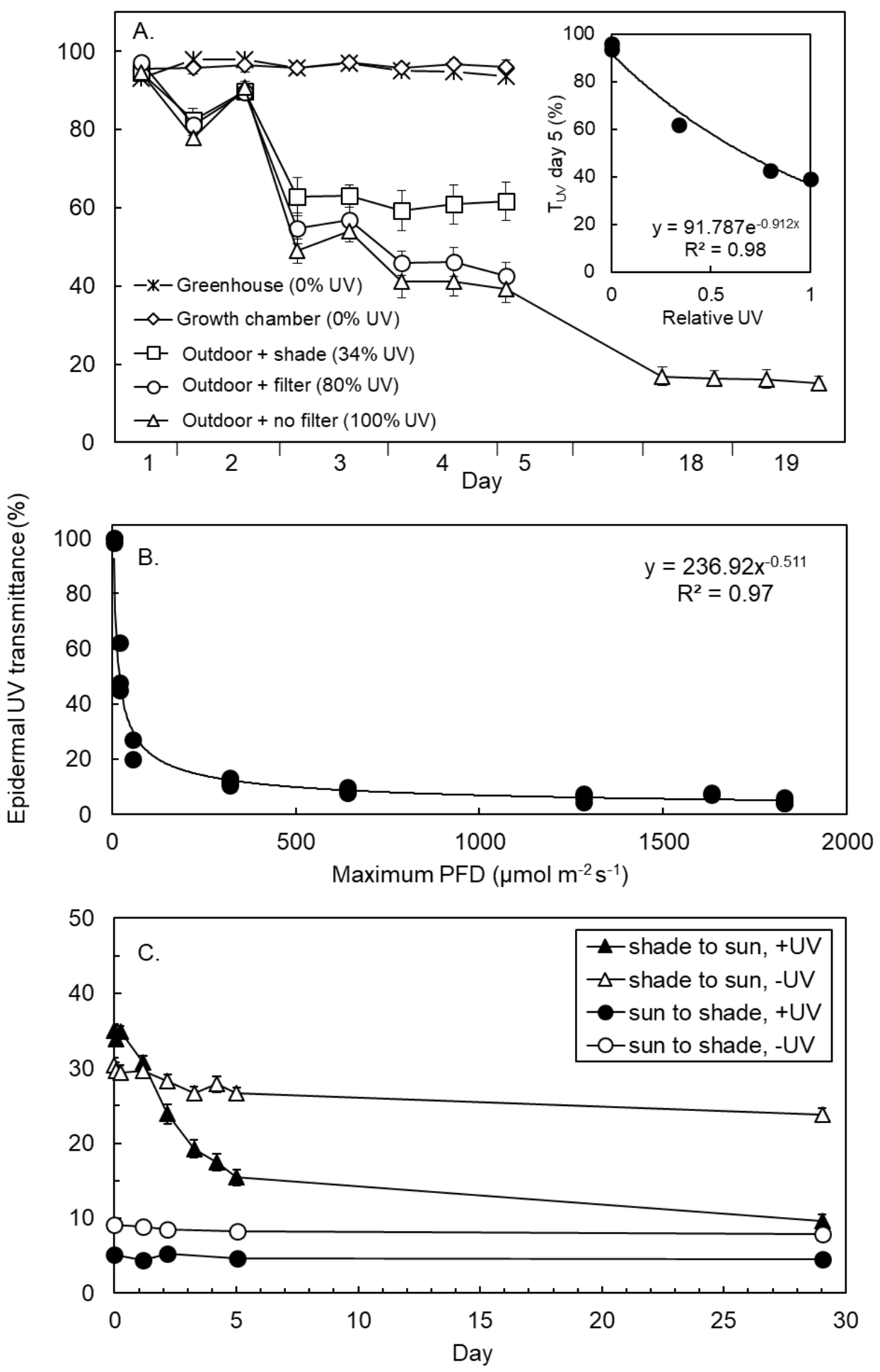
Fig 6.4

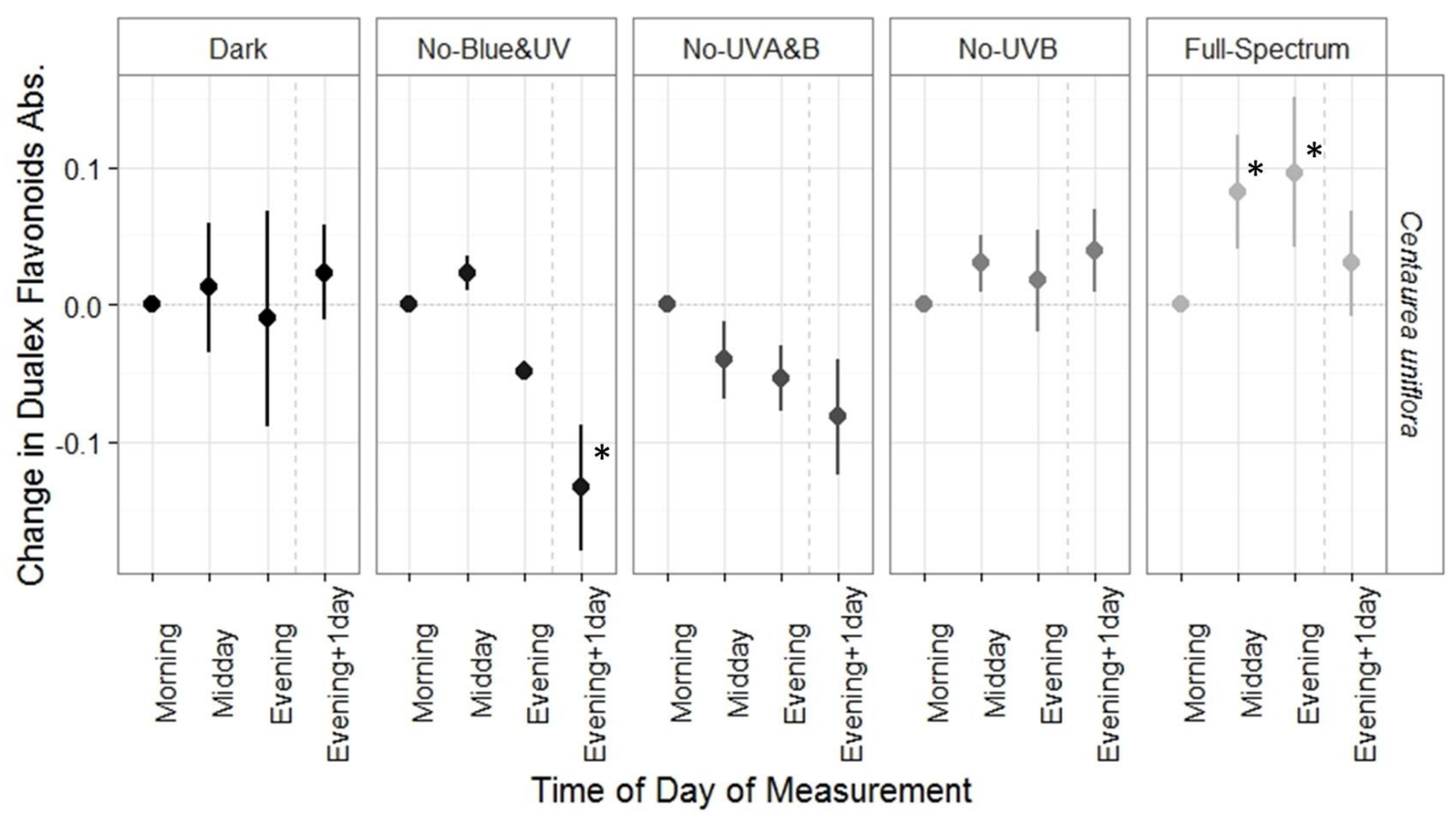


Fig. 6.5

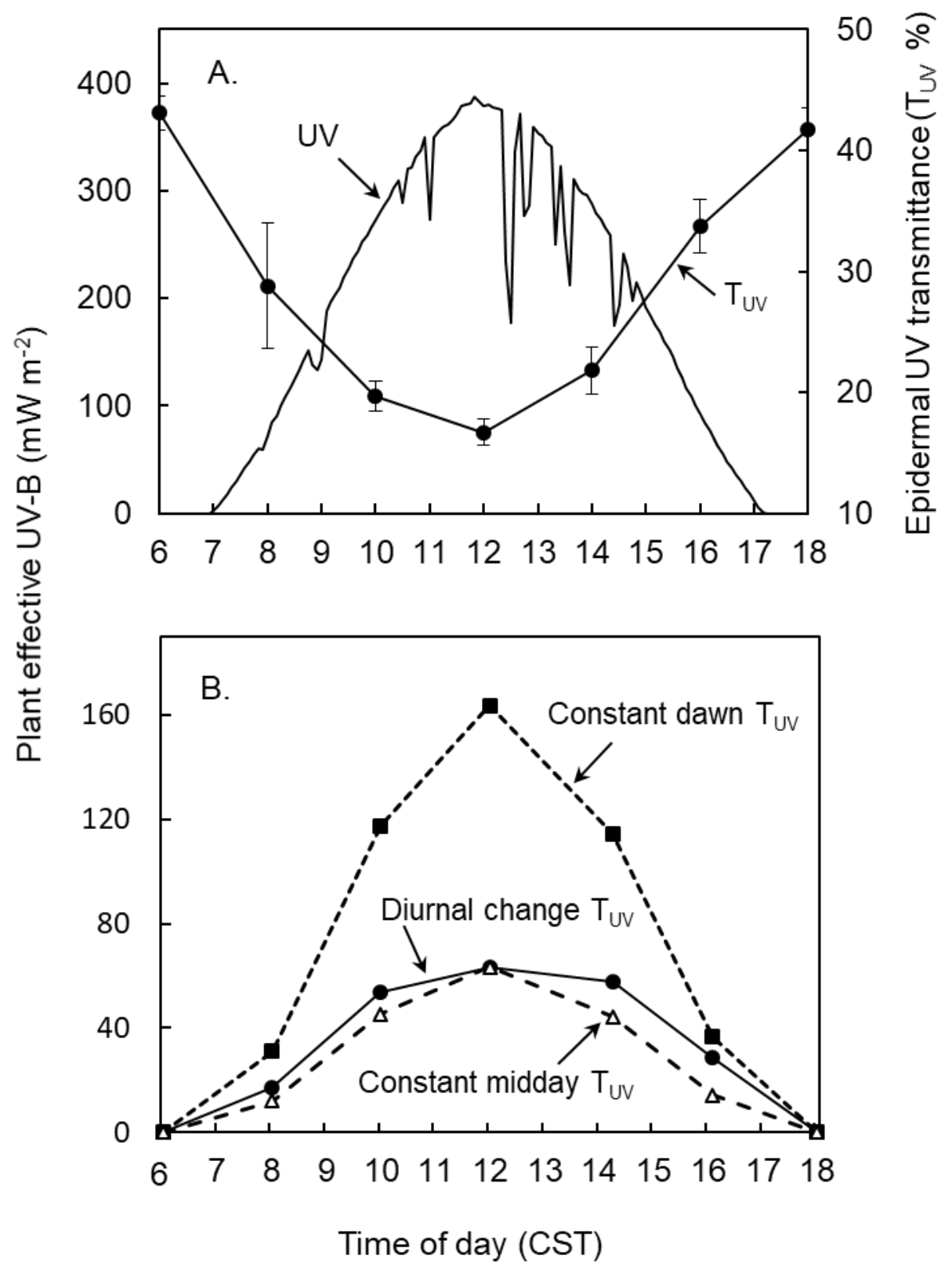


Fig 6.6

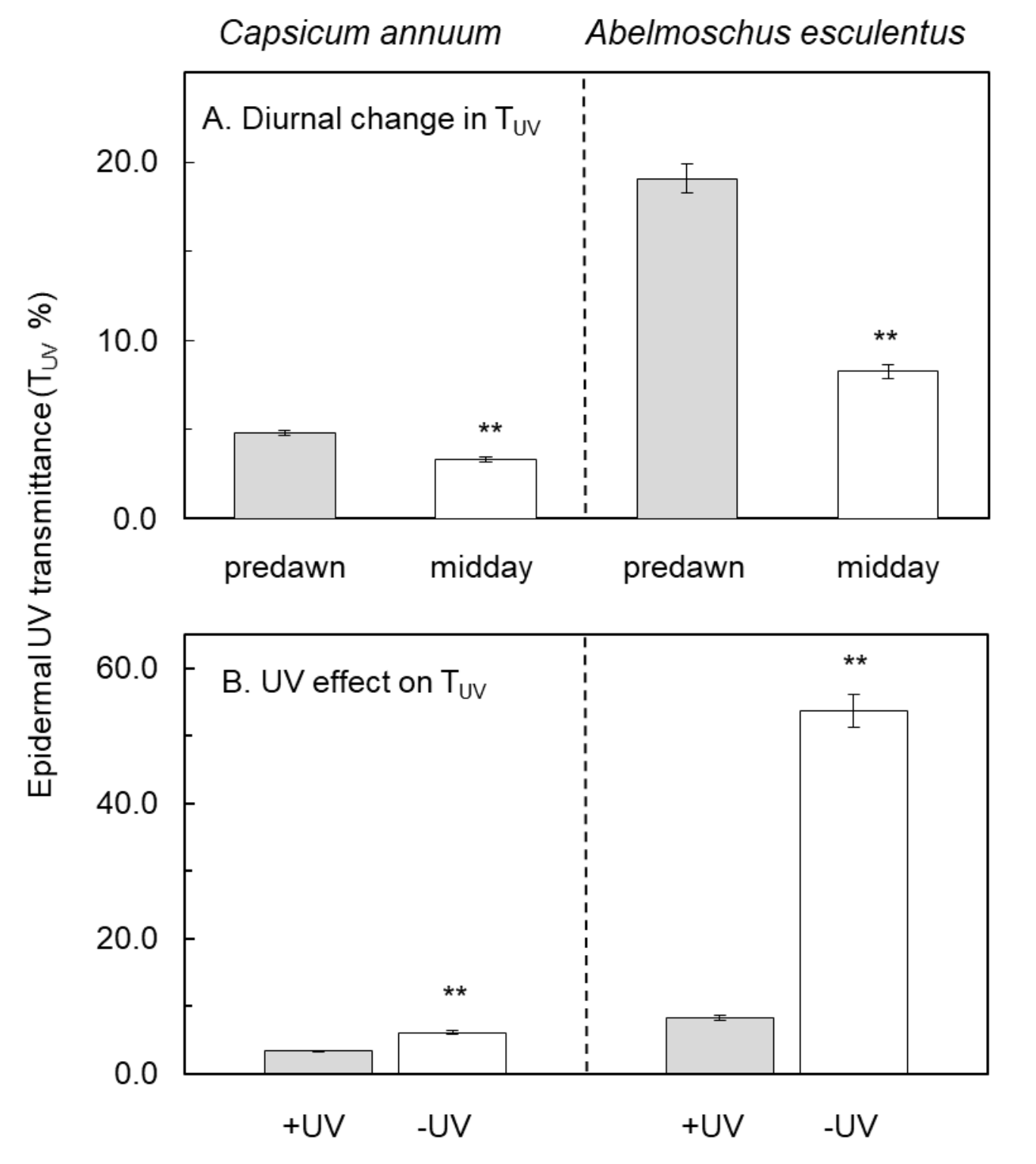

